\title{
Hubungan Keteraturan Kunjungan Antenatal Care dan Kepatuhan Konsumsi Tablet Fe dengan Kejadian Anemia pada Ibu Hamil Trimester III di Kecamatan Maron Probolinggo
}

\section{Relation between Regularity of Antenatal Care Visits and Compliance of Iron Tablets Consumption with Anemia in Third Trimester Pregnant Women in Maron Probolinggo}

\author{
Veny Nurmasari*1, Sri Sumarmi²
}

\begin{abstract}
ABSTRAK
Latar Belakang: Anemia selama kehamilan merupakan faktor risiko bagi kesehatan ibu dan janin. Pemerintah telah menerapkan distribusi tablet Fe untuk ibu hamil sebagai upaya pencegahan anemia selama kehamilan. Masalah timbul akibat ketidakteraturan ANC dan ketidakpatuhan ibu hamil dalam mengonsumsi tablet Fe.

Tujuan: Tujuan penelitian untuk menganalisis hubungan keteraturan kunjungan Antenatal Care (ANC) dan kepatuhan konsumsi tablet Fe dengan kejadian anemia pada ibu hamil trimester III

Metode: Menggunakan desain studi case controldengan besar sampel 30 yang terdiri dari 15 kasus dan 15 kontrol diambil dengan metode simple random sampling. Penelitian ini menghubungkan keteraturan kunjungan Antenatal Care (ANC) dan kepatuhan konsumsi tablet Fe dengan kejadian anemia pada ibu hamil trimester III.Penelitian dilakukan di wilayah kerja Puskesmas Maron Kabupaten Probolinggo pada bulan Mei-Agustus 2018. Analisis data yang digunakan adalah chi- square. Hasil: Hasil penelitian menunjukkan terdapat hubungan antara keteraturan kunjungan Antenatal Care (ANC) ( $p=0,001$; $\mathrm{OR}=4)$ dan kepatuhan konsumsi tablet $\mathrm{Fe}(\mathrm{p}=0,001 ; \mathrm{OR}=3,46)$ dengan kejadian anemia. Ibu hamil yang tidak teratur melakukan kunjungan ANC memiliki risiko 4 kali lebih besar untuk mengalami anemia, sedangkan ibu hamil yang tidak patuh mengonsumsi tablet Fe berisiko 3,46 kali lebih besar untuk mengalami anemia.

Kesimpulan: Keteraturan kunjungan ANC dan kepatuhan konsumsi tablet Fe berhubungan dengan kejadian anemia pada ibu hamil trimester III.
\end{abstract}

Kata kunci: anemia, antenatal care, kepatuhan

\section{ABSTRACT}

Background: Anemia during pregnancy as a risk factor for maternal and fetal health. The government has implemented iron tablet distribution for pregnant women to prevent anemia during pregnancy. Problems arasie due to non-compliance of pregnant women in consuming iron tablets.

Objectives: The purpose of the study was to analyze the correlation between regularity of antenatal care visits (ANC), and comlpliance of iron tablets consumption with anemia in third trimester pregnant women.

Method: The study used a case control study design. The samples were 30 consists of 15 cases and 15 control taken by simple random sampling method. This study correlated the regularity of ANC visits and compliance to consumption of iron tablets between regularity of antenatal care visits (ANC), and comlpliance of iron tablets consumption with anemia in third trimester pregnant women. The study was conducted in the working area of Maron Health Center Probolinggo in May August 2018. Data were analyzed using chi square.

Results: The results showed that the regularity of antenatal care visits $(A N C)(p=0.001 ; O R=4)$ and compliance of iron tablets consumption ( $p=0.001 ; O R=3.46$ ) related with anemia. Pregnant women who didn't regularly visit ANC had 4 times greater risk of anemia, while non-comliance pregnant women consume iron tablets had 3.46 times greater risk of anemia.

Conclusion: The regularity of ANC visits and compliance to iron tablet consumption were related to anemia in third trimester pregnant women.

Keywords: anemia, antenatal care, compliance 


\author{
*Koresponden: \\ venynsr@gmail.com \\ 1,2Departemen Gizi Kesehatan, Fakultas Kesehatan Masyarakat, Universitas Airlangga, \\ Kampus C Mulyorejo 66115, Surabaya, Jawa Timur, Indonesia
}

\section{PENDAHULUAN}

Indonesia merupakan negara yang memiliki tingkat Angka Kematian Ibu (AKI) tertinggi di ASEAN dan di Indonesia risiko kematian ibu karena melahirkan adalah 1 dari 65, angka tersebut tergolong tinggi apabila dibandingkan dengan negara ASEAN lainnya ${ }^{1}$. Hal inilah yang menjadikan kesehatan ibu dan janin sebagai prioritas di bidang kesehatan yang harus dicegah². Jawa Timur merupakan satu dari enam provinsi yang menyumbang AKI sebanyak $>50 \%$ di Indonesia ${ }^{3,4}$. Jawa Timur memiliki beberapa daerah dengan Angka Kematian Ibu (AKI) tinggi, salah satunya adalah Kabupaten Probolinggo. Persentase Angka Kematian Ibu (AKI) di Kabupaten Probolinggo merupakan yang tertinggi di Jawa Timur yaitu sebesar 2,21 \% ${ }^{5,6}$.

Faktor langsung dan tidak langsung merupakan dua faktor yang menyebabkan kematian ibu? Pendarahan merupakan faktor langsung yang sering menjadi penyebab kematian pada ibu hamil. Faktor kematian obsetrik juga dapat meningkatkan prevalensi angka kematian ibu ${ }^{8}$. Salah satu faktor tidak langsung yang dapat memperparah terjadinya peningkatan angka kematian ibu adalah anemia pada kehamilan ${ }^{8}$. Anemia pada saat kehamilan dapat menimbulkan berbagai risiko masalah kesehatan bahkan dapat membahayakan nyawa ibu9. Pada kehamilan dapat dikatakan anemia apabila kadar Hemoglobin dalam darah $<11 \mathrm{gr} / \mathrm{dL}^{10}$. Pada tahun 2008, prevalensi anemia ibu hamil di Asia tergolong tinggi yang mencapai $48,2 \%$. Sedangkan di Indonesia, prevalensi anemianya mencapai $37,1 \%^{11}$.Kejadian ini dapat digolongkan ke dalam masalah kesehatan masyarakat karena menurut $W H O$ prevalensi anemia dengan rentang 20-39,9\% tergolong moderate public health problem ${ }^{12}$.

Penelitian sebelumnya menyebutkan bahwa prevalensi anemia ibu hamil di Jawa Timur adalah $5,8 \%^{13,14}$. Anemia dapat ditetapkan sebagai masalah kesehatan masyarakat apabila prevalensinya di atas $5 \%$, sehingga anemia di Jawa Timur tergolong dalam masalah kesehatan masyarakat yang harus diselesaikan. Belum ada data resmi dari Dinas Kesehatan maupun literatur yang memuat prevalensi anemia pada ibu hamil di Kabupaten Probolinngo. Prevalensi anemia yang terdapat pada WUS di Kabupaten Probolinggo memiliki prevalensi anemia yang tinggi yaitu $33 \%{ }^{15}$. Angka prevalensi anemia pada WUS yang ada di Probolinggo lebih tinggi apabila dibandingkan dengan prevalensi anemia dalam skala nasional terakhir yaitu $22,7 \%^{11}$. Penelitian sebelumnya menyebutkan bahwa rata-rata prevalensi anemia pada calon pengantin wanita (CPW) di Probolinggo sebesar 48,5\%. Calon pengantin wanita tergolong dalam kelompok WUS. Pengantin wanita merupakan kelompok wanita yang nantinya akan mempersiapkan kehamilan. Pada kelompok inilah berisiko terjadi anemia dikarenakan kekurangan zat besi.
Risiko terjainya perdarahan, keguguran, BBLR, kematian ibu dan anak dapat meningkat apabila ibu hamil menderita anemia ${ }^{16}$.

Apabila dilihat dari cakupan tablet Fe di Jawa Timur, Cakupan tablet Fe di Kabupaten Probolinggo pada tahun 2015 baik Fe-1 maupun Fe-3 memiliki cakupan > 95\%. Cakupan ANC di Kabupaten Probolinggo tergolong tinggi yaitu sebesar $>98,07 \%$ pada $\mathrm{K} 1$ dan $>90,44 \%$ pada K4. Melihat cakupan tablet Fe dan ANC di Kabupaten Probolinggo yang tinggi, risiko untuk terjadi anemia dikarenakan cakupan Fe dan ANC kecil ${ }^{14}$. Penelitian sebelumnya mengemukakan bahwa terdapat beberapa faktor yang mempengaruhi terjadinya anemia pada kehamilan antara lain kepatuhan ibu hamil dalam mengonsumsi tablet $\mathrm{Fe}$, keteraturan melakukan kunjungan ANC, dan pola makan ${ }^{17}$. Anemia pada ibu hamil, khususnya anemia karena kekurangan zat besi dapat dicegah dengan pemberian pemberian tablet Fe. Upaya pencegahan dan penanggulangan anemia karena kekurangan besi telah dilakukan oleh pemerintah, yaitu dengan pemberian tablet besi atau Tablet Tambah Darah (TTD). Suplementasi TTD sebagai upaya pencegahan anemia ibu hamil diberikan sebanyak 90 butir yang dikonsumsi sehari satu tablet $(60 \mathrm{mg}$ Elemental Iron dan $0,25 \mathrm{mg}$ Asam Folat) secara berturut-turut minimal 90 hari selama masa kehamilan ${ }^{19}$. Suplementasi tablet Fe tidak akan berhasil dilakukan apabila ibu hamil tidak patuh dalam mengonsumsi tablet Fe. Ketidakpatuhan ibu hamil dalam mengonsumsi tablet Fe akan berisiko menimbulkan anemia saat kehamilan. Hasil dari penelitian sebelumnya, diketahui bahwa kepatuhan konsumsi tablet $\mathrm{Fe}$ berhubungan secara signifikan dengan kejadian anemia ${ }^{18,19,20}$. Selain kepatuhan dalam mengonsumsi tablet $\mathrm{Fe}$, anemia pada kehamilan juga dipengaruhi oleh keteraturan kunjungan pemeriksaan kehamilan atau Antenatal Care (ANC). Pemeriksaan ANC yang teratur juga menjadi salah satu faktor turunnya AKI. Pada dasarnya pelayanan ANC dilakukan untuk meningkatkan derajat kesehatan ibu hamil dan untuk memantau status kesehatan ibu selama kehamilan. Pemberian tablet Fe merupakan salah satu jenis pelayanan dari serangkaian ANC terpadu.Tablet $\mathrm{Fe}$ didapatkan ibu hamil saat kegiatan ${ }^{21}$.

Melihat gambaran kasus dan penelitian yang telah dilakukan sebelumnya penulis ingin melakukan penelitian terkait keteraturan kunjungan ANC, kepatuhan konsumsi tablet $\mathrm{Fe}$ dan kejadian anemia.Penelitian ini bertujuan untuk menganalisis hubungan keteraturan kunjungan Antenatal Care (ANC) dan kepatuhan konsumsi tablet Fe dengan kejadian anemia pada ibu hamil trimester III.

\section{METODE}

Penelitian ini merupakan jenis penelitian observasional analitik dan sebagai bagian dari penelitian 
payung yang dilakukan oleh Sri Sumarmi pada tahun 2018 dengan desain penelitian case control. Popuasi dalam penelitian adalah semua ibu hamil trimester III yang memeriksakan kehamilannya di Puskesmas Maron Kabupaten Probolinggosebanyak 65 orangdengan kriteria inklusi yaitu ibu hamil dengan kehamilan $>36$ minggu, menerima tablet $\mathrm{Fe}$, dan bersedia menjadi responden dalam penelitian. Jumlah sampel dalam penelitian sebanyak 30 orang ibu hamil, yang terbagi kedalam kelompok kasus dan kelompok kontrol. SKelompok kasus pada penelitian ini adalah ibu hamil anemia $(\mathrm{Hb}<11 \mathrm{gr} / \mathrm{dl})$, sedangkan kelompok kontrol adalah ibu hamil tidak anemia ( $\mathrm{Hb} \geq 11 \mathrm{gr} / \mathrm{dl})$. Variabel independen penelitian ini adalah keteraturan kunjungan ANC dan kepatuhan konsumsi $\mathrm{Fe}$, sedangkan variabel dependennya adalah anemia pada ibu hamil trimester III. Pengambilan sampel menggunakan teknik simple random sampling. Penelitian ini dilakukan di wilayah kerja Puskesmas Maron Kabupaten Probolinggo pada bulan Mei-Agustus 2018.

Responden merupakan ibu hamil trimester III yang diidentifikasi dari data kehamilan di wilayah kerja Puskesmas setempat. Pengambilan data dalam penelitian ini mencakup data primer dan data sekunder. Pengambilan data primer melalui wawancara menggunakan instrumen kuesioner, meliputi data karakteristik individu respoden (umur, pendidikan, dan status pekerjaan), 6 pertanyaan terkait keteraturan kunjungan ANC, dan 5 pertanyaan terkait kepatuhan konsumsi tablet Fe. Klasifikasi keteraturan kunjungan ANC dibedakan menjadi dua yaitu teratur dan tidak teratur.

Teratur, apabila ibu hamil melakukan kunjungan ANC minimal satu kali pada trimester I, minimal satu kali pada trimester II, dan minimal dua kali pada trimester ${ } I^{21}$. Tidak teratur, apabila ibu hamil tidak memenuhi kunjungan minimal pada tiap trimester. Kepatuhan konsumsi tablet $\mathrm{Fe}$ juga diklasifikasikan dalam dua kelompok yaitu ibu hamil yang patuh dalam mengonsumsi tablet Fe dan ibu hamil yang tidak patuh. Patuh apabila ibu hamil mengonsumsi tablet $\mathrm{Fe} \geq 65 \%$ dari tablet yang diberikan. Tidak patuh, apabila ibu hamil mengonsumsi tablet $\mathrm{Fe}<65 \%$ dari tablet yang diberikan.
Data kadar $\mathrm{Hb}$ diperoleh pengambilan darah dari ujung jari yang dilakukan oleh petugas medis menggunakan alat hemoglobinometer. Data sekunder merupakan penunjang data primer yang berupa data tentang kunjungan Antenatal Care (ANC) yang diidentifikasi dari buku KIA (kesehatan Ibu dan Anak). Buku KIA digunakan untuk konfirmasi kembali dari hasil wawancara menggunakan kuesioner. Data akan dianalisis menggunakan uji chi square untuk melihat hubungan antara dua variabel (dependen dan independen), sedangkan data mengenai karakteristik respondon akan dilihat distribusi frekuensi dan presentasenya. Penelitian ini telah mendapatkan persetujuan dari Komisi Etik dengan Nomor 489-KEPK tanggal 13 Agustus 2018.

\section{HASIL DAN PEMBAHASAN}

Hasil dari penelitian ini menunjukkan bahwa jumlah responden paling banyak berusia 21-35 tahun (70\%), baik pada kelompok responden anemia maupun tidak. Kondisi ini sejalan dengan penelitian yang sebelumnya, baik responden yang anemia maupun tidak anemia lebih banyak pada kelompok umur 21-35 tahun $^{16}$. Pada penelitian ini ibu hamil dengan kelompok umur risiko sebesar $30 \%$, jumlah tersebut lebih rendah jika dibandingkan dengan penelitian sebelumnya yang memiliki distribusi kelompok umur berisiko sebesar $32 \%^{7}$. Sebagian besar responden adalah ibu hamil dengan tingkat pendidikan tamat SD/Sederajat seperti pada Tabel 1, bahwa sebagian besar penduduk di Kecamatan Maron memiliki tingkat pendidikan tamat $\mathrm{SD} /$ Sederajat.

Ibu hamil yang tidak mengalami anemia paling banyak terjadi pada tingkat pendidikan tamat SD/Sederajat dan tamat SMA/Sederajat (26,67\%). Pada ibu hamil anemia paling banyak terjadi pada responden dengan tingkat pendidikan tamat SD/Sederajat responden (33,33\%). Tinggi rendahnya tingkat pendidikan ibu akan mempengaruhi banyak sedikitnya informasi yang diterima dari luar, sehingga informasi yang didapatkan ini akan meningkatkan pengetahuan yang dimiliki oleh ibu ${ }^{14}$.

Tabel 1. Karakteristik Ibu Hamil Berdasarkan Umur, Tingkat Pendidikan, dan Status Bekerja

\begin{tabular}{|c|c|c|c|c|}
\hline \multirow{2}{*}{ Karakteristik } & \multicolumn{2}{|c|}{ Anemia } & \multicolumn{2}{|c|}{ Tidak Anemia } \\
\hline & $\mathbf{n}$ & $\%$ & $\mathbf{n}$ & $\%$ \\
\hline \multicolumn{5}{|l|}{ Umur } \\
\hline$\leq 20$ dan $>35$ & 4 & 26,67 & 5 & 33,33 \\
\hline $21-35$ & 11 & 73,33 & 10 & 66,67 \\
\hline \multicolumn{5}{|l|}{ Tingkat Pendidikan } \\
\hline Tidak tamat SD/sederajat & 1 & 6,67 & 1 & 6,67 \\
\hline Tamat SD/sederajat & 5 & 33,33 & 4 & 26,67 \\
\hline Tamat SMP/sederajat & 4 & 26,67 & 3 & 20 \\
\hline Tamat SMA/sederajat & 4 & 26,67 & 4 & 26,67 \\
\hline Lulus Akademi/PT & 1 & 6,67 & 3 & 20 \\
\hline \multicolumn{5}{|l|}{ Status Bekerja } \\
\hline Tidak bekerja & 14 & 93,33 & 12 & 80 \\
\hline Bekerja & 1 & 6,67 & 3 & 20 \\
\hline
\end{tabular}


Tabel 2. Hubungan Keteraturan Kunjungan ANC dan Kepatuhan Konsumsi Tablet Fe dengan Kejadian Anemia

\begin{tabular}{|c|c|c|c|c|c|c|c|c|}
\hline \multirow{2}{*}{ Variabel } & \multicolumn{2}{|c|}{ Anemia } & \multicolumn{2}{|c|}{ Tidak Anemia } & \multirow{2}{*}{ p-value } & \multirow{2}{*}{ OR } & \multicolumn{2}{|c|}{ 95\% Cl } \\
\hline & $\mathrm{n}$ & $\%$ & $\mathrm{n}$ & $\%$ & & & Lower & upper \\
\hline \multicolumn{9}{|c|}{ Keteraturan kunjungan } \\
\hline \multicolumn{9}{|c|}{ ANC } \\
\hline Tidak teratur & 12 & 80 & 3 & 20 & 0,001 & 4 & 2,674 & 95,754 \\
\hline Teratur & 3 & 20 & 12 & 80 & & & & \\
\hline \multicolumn{9}{|c|}{ Kepatuhan konsumsi tablet } \\
\hline \multicolumn{9}{|l|}{$\mathrm{Fe}$} \\
\hline Tidak patuh & 10 & 90,9 & 1 & 9,1 & 0,001 & 3,46 & 2,821 & 277,961 \\
\hline Patuh & 5 & 26,3 & 14 & 73,7 & & & & \\
\hline
\end{tabular}

Tabel 3. Tabulasi Keteraturan Kunjungan ANC dan Kepatuhan Konsumsi Tablet Fe pada Ibu Hamil Trimester III Anemia dan Tidak Anemia

\begin{tabular}{lcccc}
\hline \multicolumn{1}{c}{ Variabel } & \multicolumn{2}{c}{ Anemia } & \multicolumn{2}{c}{ Tidak Anemia } \\
\cline { 2 - 5 } & $\mathbf{n}$ & $\mathbf{0}$ & $\mathbf{n}$ \\
\hline Tidak teratur ANC & & & & \\
$\quad$ Patuh konsumsi Fe & 5 & 33,33 & 3 & 0 \\
$\quad$ Tidak patuh konsumsi Fe & 7 & 46,67 & 0 & 73,33 \\
\hline Teratur ANC & & & & \\
$\quad$ Patuh konsumsi Fe & 0 & 0 & 11 & 6,67 \\
$\quad$ Tidak patuh konsumsi Fe & 3 & 20 & 1 & \\
\hline
\end{tabular}

Pendidikan yang baik akan mempermudah dalam penerimaan informasi atau pengetahuan baru terkait kesehatan ibu selama kehamilan. Penanganan gizi dan kesehatan dalam keluarga akan terbatas apabila ibu hamil memiliki tingkat pendidikan yang rendah. Hal tersebut tidak sejalan dengan penelitian ini karena pada dua kelompok baik ibu hamil anemia maupun tidak anemia sebagian besar berpendidikan tamat $\mathrm{SD} /$ Sederajat. Selain itu sebagian besar dari sampel dalam penelitian ini adalah ibu hamil dengan pendidikan tamat SD/Sederajat (30\%). Pada penelitian ini baik pada kelompok anemia (93,33\%) maupun tidak anemia (80\%) sebagian besar tidak bekerja. Persentase ibu hamil yang tidak bekerja lebih besar terdapat pada ibu hamil yang anemia dibandingkan dengan yang tidak anemia. Ibu hamil yang tidak bekerja memiliki risiko 1,99 lebih besar mengalami anemia apabila dibandingkan dengan ibu hamil yang bekerja, ibu hamil yang tidak bekerja merupakan faktor risiko terjadinya anemia22,23.

Berdasarkan kebijakan Departemen Kesehatan, selama kehamilan frekuensi kunjungan ANC ibu hamil sebaiknya dilakukan minimal empat kali.Penelitian ini menunjukkan bahwa ibu hamil yang tidak teratur melakukan kunjungan ANC mengalami kejadian anemia (80\%), sedangkan ibu hamil yang melakukan kunjungan ANC secara teratur tidak mengalami anemia (80\%). Ketidakteraturan ibu melakukan ANC dikarenakan banyak ibu hamil yang baru memeriksakan kehamilannya di trimester II dan III. Berdasarkan dari hasil analisis hubungan yang telah dilakukan, menunjukkan bahwa terdapat hubungan yang signifikan antara keteraturan kunjungan ANC dengan kejadian anemia $(p=0,001)$, dengan korelasi cukup $(r=0,514)$ dan dari penelitian ini juga diketahui bahwa responden yang tidak teratur melakukan kunjungan ANC memiliki risiko 4 kali lebih besar untuk terjadi anemia daripada responden yang teratur melakukan kunjungan ANC.
Ibu hamil yang melakukan pelayanan ANC lengkap akan memiliki risiko anemia lebih rendah. Pada Tabel 3 menunjukkan bahwa ibu hamil yang tidak teratur melakukan ANC dan tidak patuh mengonsumsi tablet Fe sebesar $46,67 \%$ mengalami anemia, sedangkan ibu hamil yang tidak teratur ANC akan tetapi patuh mengonsumsi tablet Fe sebesar 33,33\% mengalami anemia. Pada ibu hamil yang teratur ANC dan patuh mengonsumsi tablet Fe $73,33 \%$ tidak mengalami anemia, sedangkan ibu hamil yang teratur ANC dan tidak patuh mengonsumsi tablet $\mathrm{Fe}$ sebesar $20 \%$ mengalami anemia. Hal ini dikarenakan ibu hamil akan mendapatkan pemeriksaan anemia secara dini, mendapatkan konseling gizi yang tepat dan mendapatkan suplemen besi dan asam folat yang lengkap serta pendidikan kesehatan yang memadai, sehingga faktor risiko anemia dapat ditekan. Pelayanan ANC yang baik dan teratur akan mempermudah ibu hamil untuk memperoleh tablet $\mathrm{Fe}^{24}$. Melalui pemberian tablet $\mathrm{Fe}$ dapat meningkatkan kadarhemoglobin darah selama masa kehamilansehingga apabila dilakukanANC secara teratur dengan ketaatankonsumsi tablet Fe pada akhirnya akanmencegah terjadinya anemia. Hasil ini sejalan dengan penelitian sebelumnya bahwa terdapat hubungan pelayanan ANC dengan kejadian anemia pada ibu hamil trimester III di puskesmas Sedayu I Bantul Yogyakarta $(p=0,004)^{25}$, dan juga sejalan dengan penelitian yang lain, yang menyebutkan ANC berhubungan secara signifikan dengan anemia pada ibu hamil trimester III di Puskesmas Bernung Pesawaran $(p=0,001)^{20}$.

Pencegahan dan penatalaksanaan anemia dapat dilakukan dengan pemberian suplementasi tablet Fe selama kehamilan ${ }^{26}$. Hal ini menunjukkan bahwa kebutuhan zat besi meningkat dan tidak bisa hanya tercukupi dari asupan saja, sehingga perlu adanya suplementasi selama kehamilan. 
Suplementasi akan dapat membantu menekan kejadian anemia apabila ibu hamil patuh dan teratur dalam mengonsumsi tablet $\mathrm{Fe}^{13}$. Kepatuhan mengonsumsi tablet Fe adalah sikap yang diambil oleh ibu hamil sesuai anjuran dan petunjuk petugas medis dalam mengonsumsi tablet $\mathrm{Fe}^{27}$. Hasil penelitian menunjukkan bahwa ibu hamil yang tidak patuh mengonsumsi tablet Fe mengalami kejadian anemia $(90,9 \%)$, sedangkan ibu hamil yang patuh dalam mengonsumsi tablet Fe tidak mengalami anemia (73,7\%).

Pada penelitian ini, didapatkan bahwa kepatuhan konsumsi tablet Fe dengan kejadian anemia berhubungan secara signifikan $(p=0,001)$, dengan korelasi cukup $(r=0,528)$. Hasil dari penelitian ini juga diketahui bahwa ibu hamil yang tidak patuh mengonsumsi tablet Fe memiliki risiko 3,46 kali lebih besar untuk terjadi anemia daripada ibu hamil yang patuh mengonsumsi tablet Fe. Kepatuhan mengonsumsi tablet $\mathrm{Fe}$ sangat penting karena sel darah merah membutuhkan zat besi dalam proses sintesisnya. Pengangkutan zat gizi dan oksigen ke seluruh tubuh merupakan peran penting sel darah merah dalam tubuh serta sel membantu proses metablolisme tubuh untuk menghasilkan energy. Jika ibu hamil kekurangan zat besi dalam tubuhnya, maka akan mempengaruhi pembentukan sel darah merah. Kekurangan oksigen akan timbul apabila sel darah merah dalam tubuh mengalami kekurangan, sehingga timbul gejala anemia yang ditandai dengan penurunan kadar $\mathrm{Hb}$. Sama halnya dengan penelitian sebelumnya yang menunjukkan bahwa terdapat hubungan antara kepatuhan minum tablet besi dengan anemia ibu hamil $(p=0,001)$ dan ibu hamil akan berisiko untuk terjadi anemia 3,7 kali lebih besar apabila ibu tidak patuh dalam mengonsumsi tablet besi ${ }^{19}$. Penelitian lain menyebutkan, ketidakpatuhan ibu hamil dalam mengonsumsi tablet Fe dikarenakan lupa mengonsumsi tablet Fe. Lupa merupakan faktor penting yang menurunkan kepatuhan minum tablet besi ${ }^{28}$.

\section{KESIMPULAN}

Kesimpulan penelitian ini adalah keteraturan kunjungan ANC dan kepatuhan konsumsi tablet $\mathrm{Fe}$ berhubungan dengan kejadian anemia pada ibu hamil trimester III di Kecamatan Maron Kabupaten Probolinggo. Saran untuk ibu hamil adalah meningkatkan keteraturan kunjungan ANC, dan kepatuhan konsumsi tablet Fe serta turut aktif dalam mengikuti penyuluhan yang diadakan oleh petugas kesehatan.

\section{ACKNOWLEDGEMENT}

Peneliti mengucapkan terimakasih kepada seluruh bidan, kader, petugas laboraturium, dan petugas kesehatan lain di Puskesmas Maron Kabupaten Probolinggo atas bantuan yang diberikan selama proses pengambilan data. Peneliti juga mengucapkan terimakasih pada ibu hamil atas keikutsertaannya dalam penelitian ini.

\section{REFERENSI}

1. Kementrian Kesehatan RI. Infodatin Data and Information Center Ministry of Health Republic of Indonesia (Mother's day). (2014).

2. Handayani. Faktor-faktor yang Berhubungan dengan Kejadian Anemia pada Ibu Hamil Trimester III di Wilayah Puskesmas Liang Anggang Kota Banjarbaru Kalimantan Selatan. (Universitas Indonesia, 2012).

3. Departemen Kesehatan RI. Profil Kesehatan Indonesia Tahun 2015. Profil Kesehatan Indonesia Tahun $2015 \quad$ (2015). doi:10.1111/evo.12990

4. Kementrian Kesehatan RI. Profile Kesehatan Indonesia Tahun 2017. Ministry of Health Indonesia (2018). doi:10.1002/qj

5. Dinas Kesehatan Kabupaten Probolinggo. Profil Kesehatan Kabupaten Probolinggo Tahun 2016. (2016).

6. Dinas Kesehatan Provinsi Jawa Timur. Profil Kesehatan Provinsi Jawa Timur Tahun 2016 [East Java Health Profile 2016]. (2016).

7. Aprilisa, S. Yulifa, R. S. Hubungan Anemia Pada Ibu Hamil dengan Berat Badan Bayi Baru Lahir di Bidan Praktek Swasta Kertosuko Kecamatan Krucil Kabupaten Probolinggo. 2, 403-413 (2017).

8. WHO. Global Nutrition Targets 2025 Policy Brief Series. WHO Int (2014). doi:10.2165/00024677200302060-00002

9. Al-Farsi, Y. M. et al. Effect of high parity on occurrence of anemia in pregnancy: A cohort study. BMC Pregnancy Childbirth 11, 7 (2011).

10. Yanti, D. E. Hubungan Kepatuhan Konsumsi Tablet Fe dengan Kejadian Anemia pada Ibu Hamil Trimester III di Puskesmas Bernung Kabupaten Pesawaran 2016. J. Dunia Kesmas 5, 139-145 (2016).

11. Putri, P. H., Sulistyono, A. \& Mahmudah. Analisis Faktor yang Mempengaruhi Anemia pada Kehamilan Usia Remaja. J. Maj. Obstet. Ginekol. 23, 33-36 (2015).

12. World Health Organization, W. The Global Prevalence of Anemia In 2011 WHO Library Cataloguing-in-Publication Data. the Global Prevalence of Anaemia in (2011). doi:10.1111/j.1600-0854.2007.00534.x

13. Fatkhiyatur, R., Atmono, D., Widodo, A. \& Wulandari, P. Faktor risiko penyakit anemia gizi besi pada ibu hamil di jawa timur. J. Sains dan Seni ITS 4, 0-5 (2015).

14. Natalia, S., Sumarmi, S. \& Nadhiroh, S. R. Cakupan Anc Dan Cakupan Tablet Fe Hubungannya Dengan Prevalensi Anemia Di Jawa Timur. Media Gizi Indones. 11, 70 (2017).

15. Sahana, O. N. \& Sumarmi, S. Hubungan Asupan Mikronutrien Dengan Kadar Hemoglobin Pada Wanita Usia Subur ( Wus ). Media Gizi Indones. 10, 184-191 (2015).

16. Riskesdas Batlibangkes. Riset Kesehatan Dasar 2013. Riset Kesehatan Dasar 2013 6, (2013). 
17. Pavord, S. et al. UK guidelines on the management of iron deficiency in pregnancy. $B r$. J. Haematol. 156, 588-600 (2012).

18. Mandariska, C. P. \& Sarwinanti, S. Hubungan Kepatuhan Meminum Tablet Fe Terhadap Kejadian Anemia Pada Ibu Hamil Trimester III di Puskesmas Kalikajar I Wonosobo. (Sekolah Tinggi Ilmu Kesehatan 'Aisiyah Yogyakarta, 2015).

19. Sumarmi, S., Puspitasari, N., Handajani, R. \& Wirjatmadi, B. Underweight as a risk factor for Iron depletion and Iron- Deficient erythropoiesis among young women in Rural Areas of East Java, Indonesia. Malays. J. Nutr. 22, 219-232 (2016).

20. Utomo, A. P. W., Nurdiati, D. S. \& Padmawati, R. S. Rendahnya asupan zat besi dan kepatuhan mengonsumsi tablet besi berhubungan dengan kejadian anemia pada ibu hamil di Wilayah Kerja Puskesmas I Kembaran, Banyumas. J. Gizi dan Diet. Indones. (Indonesian J. Nutr. Diet. 3, 41 (2016).

21. Direktorat Bina Pelayanan Medik Dasar. in Pedoman Pelayanan Antenatal 1 of 98 (2007).

22. Destaria, S. \& Pramono, B. Perbandingan Luaran Maternal dan Perinatal Kehamilan Trimester Ketiga Antara Usia Muda dan Usia Reproduksi sehat. 1-20 (2011).

23. Notoadmodjo, S. in IImu Perilaku Kesehatan 9-
10 (PT Rineka Cipta, 2013).

24. Melku, M., Addis, Z., Alem, M. \& Enawgaw, B. Prevalence and Predictors of Maternal Anaemia during Pregnancy in Gondar, Northwest Ethiopia: An Institutional Based Cross-Sectional Study. Volume 2014, Article ID 108593, 9 pages http://dx.doi.org/10.1155/2014/108593. Hindawi Publ. 2014, (2014).

25. Fatimah \& Ernawati, S. Pelaksanaan Antenatal Care Berhubungan dengan Anemia pada Kehamilan Trimester III di Puskesmas Sedayu I Yogyakarta. J. Ners dan Kebidanan Indones. 3, 134-139 (2016).

26. Bothwell TH. Iron Requirements in Pregnancy and Strategies. Am J Clin Nutr 72, 257-264 (2008).

27. Obai, G., Odongo, P. \& Wanyama, R. Prevalence of anaemia and associated risk factors among pregnant women attending antenatal care in Gulu and Hoima Regional Hospitals in Uganda: A cross sectional study. BMC Pregnancy Childbirth 16, 1-7 (2016).

28. Hadi, H. Widagdo, D. Lestariana, W. Pengaruh Suplementasi Tablet Fe dengan Supevisi Suami pada Ibu Hamil Terhadap Umur Kehamilan di Kabupaten Bantul. J. Gizi Klin. Indones. 2 No. 1, 22-27 (2015). 